\title{
Hukuk Eğitimi ve Uygulamasında Yaratici Drama
}

\author{
Fahrettin KAYHAN. \\ Fikrî Mülkiyet Hukukçuları Derneği
}

\begin{abstract}
Özet
Oyun, yaratıcı drama ve hukuk kavramları arasında yakın ilişkiler vardır. Muhakeme Hukuku Tarihi incelendiğinde, ilk çağlardan günümüze kadar davanın büyük ölçüde bir "yarışma” olarak gerçekleştiğini gözlemliyoruz. Oyunun biçimsel özellikleri arasında en önemlisi, oyun etkinliğinin olağan hayattan uzam olarak ayrılmış olmasıdır. Benzer şekilde, yargılama etkinliği de tarih boyunca, az ya da çok bu işlev için organize edilmiş "uzman" mekânlarda bir tören biçiminde yürütülmüşürr. Oyunun diğer bir özelliği, onun "gündelik" ve "asll hayat" olarak kabul edilmemesidir. Oyunun bir başka özelliği, oyun uzamının sınırları içinde kendine özgü ve mutlak bir düzenin egemen olmasıdır. Bu düzen her oyunun kendi kurallarlyla belirlenir. Bir oyunun kurallarl, mutlak olarak emredici ve tartışılmazdır. Bir davada oynanan oyunun kurallarını muhakeme hukuku belirler. Yargılama kuralları, diğer hukuk kurallarına göre çok daha biçimsel, katı ve bu yönüyle de oyunsudur. Yaratıcı drama, tanımının unsurları arasında yer alan "oyun" kavramı, yukarıdaki açılklamalarımız çerçevesinde, yaratıcı drama ile hukuk arasındaki ilk güçlü bağı oluşturmaktadır. Ancak bu iki kavram arasındaki bağ, bundan ibaret değildir. Tanımdan anlaşılacağı üzere, yaratıcı drama doğaçlama ve rol oynama gibi tiyatro tekniklerinden yoğun olarak yararlanır. Tüm bu benzerlikler, hukuk eğitimi ve uygulamasinda yaratıcı dramadan yararlanmayı zorunlu kilmaktadır.
\end{abstract}

Anahtar sözcükler: hukuk ve yaratıcı drama, hukuk eğitimi, hukukçu eğitimi, hukuk ilintili yurttaşllk eğitimi

\begin{abstract}
There is a close relationship between play, creative drama and law. When the history of procedural law is examined, we observe mainly a trial as a "competition" from antiquity to today. The most important formal characteristic of play is that the activity of play is separated from ordinary life as a space. Accordingly during the history, the activity of trial has been conducted in the private places which have been organized for this purpose. One of the characteristics of play is that play is not accepted as "daily life" and "real life". Another characteristic of play is that there is a special and absolute order is dominated in the borders of the scope of play. This order is determined by the own rules of every play. The rules of a play are absolutely imperative and indisputable. The procedural law determines the rules of the play in trial. The procedural rules are more formal and rigid than the other legal rules, therefore are like a play. The concept of "play" which is one of the elements of the description of creative drama forms the first powerful connection between creative drama and law in the frame of my statement above. However the connection between two concepts does not only consist of this element. As understood by the description, creative drama uses some theatrical techniques such as improvisation and role play. These all similarities necessitate to use creative drama in law education and practice.
\end{abstract}

Keywords: Law and creative drama, law education; education of jurist, citizenship education related law.

·Avukat, Fikrî Mülkiyet Hukukçuları Derneği, E-posta: fahrettin.kayhan@kayhan-akilli.av.tr 


\section{Giriş}

Yaratıcı dramanın kullanım alanlarını sınırlı olarak belirlemek olanaksızdır. Yaratıcı drama, örgün, yaygın ve hizmet içi eğitimde başlı başına ayrı bir ders olarak verilebileceği gibi, diğer derslerin öğretiminde de bir yöntem olarak kullanılabilir. Bunun dışında yaratıcı dramanın, psikolojik danışmanlık ve rehberlik aracı olarak hastanelerde, ceza ve tutukevlerinde, sslahevlerinde kullanılma potansiyeli vardır (Okvuran 2006, s.196). Bu makalede, yaratıcı dramadan hukuk eğitimi ve uygulamasında yararlanma olanağı üzerinde durulacaktır.

\section{Hukuk Öğretimi ve Hukuk Ĕgitimi}

"Hukuk öğretimi” veya "hukuk eğitimi”" terimleri, yaygın olarak, toplumda hukukçu olarak görev yapacak kişilerin yetiştirilmesi etkinliğini ifade etmek için kullanılmaktadır.

Karayalçın (1994, s.4,) eğitim kavramını, "insanların bilgilerini, davranışlarını, bedeniahlâki- fizikî kabiliyetlerini, düşünme, yaratma, problem çözme, karar verme, uygulama güçlerini oluşturmak ve geliştirmek için yapılan çalışmaların tümü" olarak tanımlarken; "öğretim"i genel ve üst kavram olan "eğitime" göre sınırlı bir kavram olarak kabul etmektedir. Karayalçın'a göre öğretim, kişiye "bilgi aktarma" işlemidir. Ertürk'e göre (Akt.: Demirel ve Kaya, 2006, s.6) göre ise "eğitim", önceden saptanmış ilkelere göre insanların davranışlarında belli gelişmeler sağlamaya yarayan planlı etkilikler dizgesi; bireyin davranışlarında kendi yaşantısı yoluyla kasitlı olarak istenilen yönde değişme oluşturma sürecidir.

$\mathrm{Bu}$ makalede, "Hukuk eğitimi" terimi, aksi belirtilmediği sürece yalnızca "hukukçu eğitimi”ni ifade etmek için değil, onu da kapsayacak şekilde her düzeydeki hukuk ilintili yurttaşlık eğitimini (law related education) de içerecek biçimde en geniş anlamıyla kullanılmıştır.

Türkiye'de yaratıcı dramanın hukuk eğitiminde kullanılmasının hukuk ilintili yurttaşlık eğitimi ile ilgili olarak başladığını söylemek mümkündür. Üstündağ’ın (1997) İlköğretim sekizinci sınıflarda okutulmakta olan Vatandaşlık ve İnsan Hakları Eğitimi dersinde yer alan "Hürriyetçi Demokrasimizde Temel Hak ve Ödevlerimiz" ünitesinin öğretiminde yaratıcı dramanın öğrencilerin erişilerine etkilerini araştıran çalışması bu görüşü destekler niteliktedir.

Lisans düzeyinde hukukçu eğitiminde ise 6070 yıl öncesinin özel koşullarına göre benimsenen eğitim yöntemleri gelenek haline gelmiş, yetersizliği ilgili herkes tarafından kabul edilmesine karşın hâlâ sürdürülmeye çalışılmaktadır (Güran, 2003, s.86) Çok kalabalık sınıflarda anlatma (takrir) yöntemiyle hukuksal bilgi öğrencilere aktarılmaya çalışılmaktadır. Anlatma yöntemi, daha çok "yorumlayıcı", "açımlayıcı", "belirtici" ve "aydınlatıcı" özellikleriyle öğretimde olumlu yönleri olmakla birlikte; öğretici merkezli olması, öğrencide koşulsuz itaat üretmesi, katılımcı olmaması yönüyle eleştirilmektedir (Pekcanıtez, 2006, s.3). Hukuk Fakültelerinde zaman zaman "pratik çalışma" adı altında uygulamalı çalışmalar yapılmaya çalışılsa bile, bu etkinliğe bir sınıftaki yüzlerce öğrenciden ancak üç veya beş kişinin katılımı sağlanabilmektedir (Güran, 1987).

Genel durum bu olmakla birlikte, son zamanlarda, klasik hukuk eğitimine alternatif arayışlar da ortaya çıkmaya başlamıştır. Bu arayışlardan biri ülkemizde önce tıp eğitimi alanında başlayıp, daha sonra diğer alanlara yayılamaya başlayan "Probleme Dayalı Eğitim" yöntemidir. 15-20 kişilik öğrenci gruplarıyla, eğitim yönlendiricisinin liderliğinde, disiplinler arası ve gerçekçi yaklaşımla hazırlanmış senaryolara dayalı tartışmacı ve katılımcı bir yöntem olan probleme dayalı eğitim yöntemi, kurgusal yapısı itibarıyla kısmen yaratıcı dramayı andırmaktadır 
Gerek hukuk fakültelerinde, gerekse barolarda "farazi mahkeme", "sanal dava" veya "kurgusal duruşma" adı altında kısmen canlandırmaya dayalı yarışmalar düzenlenmektedir. $\mathrm{Bu}$ yarışmalar, belirli ölçüde yaratıcı drama içermektedir. Ancak, bu etkinliğe katılımın sayısal olarak sınırlı olması; yaratıcı dramanın aksine tiyatrodaki oyuncu- seyirci ayrımını barındırmas1; rollerdeki ve canlandırmalardaki sınırlılık bu yarışmaları yaratıcı dramadan da farklı kılan özelliklerdir.

Doğu Akdeniz Üniversitesi Hukuk Fakültesinde bir grup gönüllü felsefe öğrencisi tarafindan 21-25 Mayıs 2004 tarihleri arasında düzenlenen bir atölye çalışmasında eski Türk Ceza Kanunun zina suçu ile ilgili 438. maddesi ile ilgili olarak drama çalışması yapılmıştır (Öntaş 2004, s.90). Bu çalışma hukuk eğitiminde yaratıcı dramanın yöntem olarak uygulandığına ilişkin örnek olarak verilebilir.

Adalet Bakanlığı Hakim Savc1 ve Adayları Eğitim Merkezi'ndeki staj eğitiminde, yaratıcı dramaya benzer yöntemleri uygulanmaktadır. Çamlıbel'e (2006, s.215) göre Merkez'de uygulamaya yönelik olarak 22 ders verilmekte, adaylara cüppe giydirilerek, ilgili daire dosyaları senaryolaştırılarak yargılama süreci canlandırılmaktadır.

Türkiye'de Hukuk alanında yaratıcı dramanın kullanılmasına ilişkin başka bir çalışma, Fikri Mülkiyet Hukukçuları Derneğinin 18 Ağustos 2006 tarihindeki "Ütopya Buluşması" etkinliğinde Çağdaş Drama Derneği drama liderleri Dr. Fatma Akfırat ve Fevzi Bakır'ın yönettiği "FMDER Drama Atölyesi”dir. Bu çalışma, Av. Ayşen Merih Acar ve Ankara Barosu Yönetim Kurulu üyesi Av. Fahrettin Kayhan'ın girişimiyle Ankara Barosu'na taşınmış ve Ankara Barosu tarafından "Yaratıc1 Drama ve Avukatlık Sanatı" konulu bir konferans gerçekleştirilmiştir. Av. Ayşen Merih Acar yönetiminde 29 Eylül 2006 tarihinde gerçekleştirilen konferansa Çağdaş Drama
Derneği Genel Başkanı H. Ömer Adıgüzel, İstanbul Barosu avukatlarından Av. Kâmil Kirman ve Fahrettin Kayhan konuşmacı olarak katılmışlardır. Konferansta yaratıcı dramanın genel tanımı ve bileşenleri üzerinde durularak, hukuk ve avukatlık eğitiminde yaratıcı dramanın olası yararlarına değinilmiştir. Bu konferansın ardından Çağdaş Drama Derneği ile Ankara Barosunun işbirliğiyle "Hukukçular İçin Yaratıcı Drama Liderliği” programı başlatılmıştır; programın temel aşaması Şubat 2007'de tamamlanmıştır. Av. Ayşen Merih Acar, liderlik projesi olarak "Yaratıcı Drama Yöntemiyle Türk Yarg1 Sistemindeki Duruşmalarda İletişim Becerisi ve İletişim Engelleri Konusunda Farkındalık Geliştirme" başlıklı projeyi hazırlamış ve uygulamaya koymuştur.

\section{Yaratıcı Drama ve Hukuk İlişkisi}

Adıgüzel'e (2006, s.17) göre, "Yaratıcı drama, herhangi bir konuyu, doğaçlama, rol oynama gibi tekniklerden yararlanarak, bir grupla ve grup üyelerinin birikimlerinden, yaşantılarından yola çıkarak canlandırmalar yapmaktır. $\mathrm{Bu}$ canlandırmada oyunun genel özelliklerinden yararlanılır."

Yaratıcı drama tanımının kurucu öğeleri olan "oyun" ve "canlandırma" kavramları ile "hukuk" terimlerinin birbiriyle ilişkisi olduğunu ilk bakışta algılamak ve kabul etmek güçtür. Gerçekten de, ortalama bir alg1 için "oyun", "drama" ve "hukuk" tamamen farklı evrenlere ait kavramlar olarak gözükür. Hukuka ilişkin her şeye kutsal, adeta semavi bir ciddiyet hakimdir. Buna karşıllk "oyun" ise ciddi bir etkinlik olarak görülmez. Bu nedenle, "oyun", "drama" ve "hukuk" kavramları arasında bir akrabalığın olabileceği başlangıçta kabul görmeyecektir. (Kayhan 2006b, s.57). Bu nedenle önce oyun-hukuk ilişkisi üzerinde durulacaktır.

Oyun-ciddiyet karşıtllı̆ğ, "oyun ciddî değildir" önermesi olarak ele alındığında, bu iki kavram arasında kurulan karşıtlık ilişsisinin geçerli 
olmadığını gösterir. Gerçekten de futbol, satranç, basketbol gibi pek çok oyun çocuklar ve yetişkinler tarafindan büyük bir ciddiyet içinde oynanırlar (Huizinga, 2006, s.22). Hatta, bir çok oyunun kuralları, aynı zamanda hukuk kuralı haline gelmiş; "spor hukuku", "oyun hukuku” gibi ayrı hukuk disiplinleri oluşmuştur. Bir oyunla ilgili ortaya çıkan hukuksal uyuşmazlığın, daha ciddi kabul edilen yaşam alanlarıyla ilgili hukuksal uyuşmazlıklara göre kamuoyu tarafindan daha fazla ciddiye alındığını söylenebilir.

Bu nedenle, oyun ve hukuk arasında kurulacak bağlantıya, oyun-ciddiyet karşıtlığına dayanarak karşı çıkmak mümkün görülmemektedir.

Muhakeme hukuku tarihi, ilk çağlardan günümüze kadar davanın büyük ölçüde bir "yarışma" olarak cereyan ettiğini kanıtlıyor. Eski Yunanda dava, kesin usul kurallarına tabi, belirli formlara bağlı olarak icra edilen ve tarafların hakemin kararlarına uydukları bir yarışmadan başka bir şey değildir. Davanın "yarışmacı" karakteri bu güne kadar varlığını sürdürmüştür. Yarışmanın söz konusu olduğu yerde oyunsallık ve dramatik durum vardır.

Oyunun biçimsel özellikleri arasında en önemlisi, oyun, etkinliğinin olağan hayattan uzam olarak ayrılmış olmasıdır. Oyun kuralları, oyun işlevi için özgülenmiş bu uzam içinde geçerlidir. Oyun uzamı, gündelik çevreden fiziksel ve düşünsel olarak soyutlanmış ve ayrılmıştır (Huizinga, 2006).

Gündelik hayattan soyutlanmış bir uzamın belirlenmesi, aynı zamanda her ciddi ve kutsal eylemin en belirgin özelliğidir (Yeğin, 2003). Bütün rahipliğe atama ve eriştirme ayinleri, herhangi bir mesleğe kabul törenlerinin söz konusu olduğu her yerde soyutlanmış bir uzamın özgülenmesi söz konusudur. Benzer şekilde, yargilama etkinliği de tarih boyunca, az ya da çok bu işlev için organize edilmiş uzman mekânlarda bir tören biçiminde yürütülmüştür. Adlî uzam günlük hayattan ayrılmış ve sınırlandırılmış kutsal bir alandır. Roma Usul Hukukunda kelime kelime saptanarak düzenlenmiş olan legis actio'lar, bazı belirli bedensel pratikler icra edilerek bir tür ilahi gibi okunmaktaydı. $\mathrm{Bu}$ ritüele uygun olarak yargıçların davalara baktığı, tarafların sırasını beklediği, halkın davaları izleyebildiği "bazilika" adı verilen binalar tasarlanmıştır. Bugün de, yargılama uzamları, "duruşma salonu", "adliye sarayı", "adliye binası" gibi terimlerle kavramlaştırılmakta ve bu uzamlar, yasalarda özel düzenlemelerin konusu olabilmektedir (Kayhan, 2006a, s.355).

Özetle oyun faaliyeti ve yargılama faaliyeti, gündelik hayattan fiziksel ve düşünsel olarak soyutlanmış bir uzam içinde cereyan etmektedir.

Oyunun bir başka özelliği, oyun uzamının smırları içinde kendine özgü ve mutlak bir düzenin egemen olmasıdır. Bu düzen her oyunun kendi kurallarıyla belirlenir. Bir oyunun kuralları, mutlak olarak emredici ve tartışlmazdır. $\mathrm{Bu}$ düzenin her hangi bir şekilde ihlali oyunu bozar; ihlâl oyunu yok eder. Çünkü onları belirleyen ilke tartışmasız niteliktedir. Kurallar ihlal edilir edilmez, oyun evreni çöker, oyun diye bir şey ortada kalmaz. Hakemin düdügü büyüyü bozar ve 'bildik dünya'nın mekanizmasını bir an için geri getirir." Kurallara uymayan veya karşı çıkan oyuncu, oyunbozandır. Oyunbozan mızıkçılık ederek, oyun arkadaşlarıyla birlikte kapandığ1 oyun evrenin göreceliliğini ve kırılganlığını ortaya koyar. Mızıkçı, oyuncuların varlığını tehdit eden bir unsur olduğundan derhal oyundan atılır (Huizinga, 2006, s.29). Bir davada oynanan oyunun kurallarını muhakeme hukuku belirler. Yargılama kuralları, diğer hukuk kurallarına göre çok daha biçimsel, katı ve bu yönüyle de oyunsudur.

Oyunun diğer bir özelliği, onun "gündelik" ve "asıl hayat" olarak kabul edilmemesidir. Oyun, oynayana, gündelik yaşamdan kaçarak, kendine özgü evreni olan bir faaliyet alanına girme 
bahanesi verir. Oyun gündelik hayattan, bu hayatın işgal ettiği yer ve zamanla ayrılır. Bu yalıtılmışlık oyunun diğer belirleyici özelliğidir (Huizinga, 2006, s. 27). Yargilama faaliyeti de, "gündelik" ve "asıl" hayattan ayrılmaktadır. Yargılama faaliyeti, bu faaliyete katılanların yargılama esnasında cüppe, peruka gibi özel kostümler giymesiyle olağan yaşamdan ayrılmaktadır (Kayhan, 2006a). Bu özel kisvelerin fonksiyonları, ilkel toplumların dans maskelerinin işlevlerine çok benzemektedir. Yargısal kisveleri giyenler, adeta farklı bir varlığa dönüşmektedir.

Davanın ilkel biçimlerine doğru geriye gittiğimizde oyunla hukuk arasındaki farkın iyice yok olduğunu görüyoruz. İlkel uygarlıklarda dava bir talih oyunudur: Kâhine başvurarak, fal açarak yani oyun aracığıyla yargısal kararlar verme dönemidir bu. Fal açarak yargısal karar vermenin örneklerine kutsal kitaplarda rastlamaktayız. Örneğin Saul, kendisi ile oğul Yonatan arasındaki bir davayı karara bağlamak üzere fal açılmasını emretmiştir (I, Samuel.XIV, 42). Hukuk ve şans arasındaki bağa, bir kur'a çekimine hukuksal sonuç bağlayan hukuk kurallarına bu gün bile kimi hukuksal düzenlemelerde rastlamak mümkündür.

Yargısal karar, bazen bir yarış veya karşılaşmanın sonucuna göre belirlenmiştir. Germanik halkların hukuklarında, toprak mülkiyetinin sınırları kimi zaman bir yarış veya bir baltanın firlatılması yoluyla belirlenmekteydi. Bir davada karar, gözleri bağlanmış bir kimsenin bir kişiye dokunmasına göre verilmekteydi. $\mathrm{Bu}$ yöntemin bildiğimiz körebe oyunuyla benzerliği düşünülmelidir.

Arkaik dönemde yargılamada sonucu, kanıtların değil de en ağır tutarlı hakaretin belirlediği sözlü çekişme yöntemini anmak gerekir. Burada yargılama süreci, bütünüyle hakaret yüklü söylevlerle rakibe üstün gelme esasına dayalıdır. Gronland Eskimolarındaki davul ve şarkı yarışmaları incelendiğinde oyun ile yargılama arasındaki bağ açıça ortaya çıkmaktadır. Yakın geçmişe kadar sürdürülen bu adli geleneğe göre, bir Eskimo diğerinden şikâyetçi olduğunda, onu bir davul veya şark1 yarışmasına davet eder. Kabile bir bayram havasında toplanır. Taraflar davul eşliğinde karş1lıklı olarak hakaret yüklü şarkılar söyler ve karşı taraf hakkındaki kötü duygularını aktarır. Bu şarkılarda, davanın dayağı olan itham, hiciv ve iftira arasında bir ayrım yapılmaz. Şarkılara fiili tecavüzler; hatta karşı tarafın yüzüne hapşırmak, tükürmek, kafa atmak, ağzını zorla açmak gibi kötü muameleler eklenmektedir. Sanık bütün bunlara iyi niyetle ve hatta gülümsemeyle katlanmak zorundadır. İzleyiciler, şarkıların nakaratlarına eşlik eder, alkışlayarak tarafları tahrik eder. Celse aralarında rakipler birbirine arkadaşça davranır. Oturumlar sonucunda izleyiciler kimin haklı olduğuna karar verir. İlginç olan bu yarışma sonuçlarının uygulandıkları kabilelerde adli karar yerine geçmesidir. $\mathrm{Bu}$ kabilelerde cinayet davaları bile bu yolla çözülmektedir. Bu yöntemde oyun içinde ve oyun yöntemiyle hukuksal uyuşmazlıklar çözülmektedir (Huizinga, 2006, s.106).

Antik Yunanda hakaret yarışması ve yargılamanın iç içe olduğunu anlaşılmaktadır. Atina'nın en görkemli döneminde adli hitabet, aynı zamanda bütün hilelere ve ikna etmeye yönelik tüm yöntemlere izin veren bir beceri yarışmasıydı. Sofistler, haksız bir davayı haklı gösterme sanatını parayla öğretmekteydiler. Roma'da ise rakibi mahkemede haksız çıkarmak için bütün yöntemler uzun süre meşru sayılmıştır. Mahkemelerde matem giysileri giyilmekte, iç geçirip, yakarılmaktadır. Advokatiler, savunmalarını daha etkili k1labilmek için yargılamanın en kritik- önemli anında tezahüratta bulunacak alkışlayıcılar tutarlardı. Bunlara lavdiceni denir, yaptıkları tezahüratın ücretini advocatilerden alırdı (Bozkurt, 2006, s.67). Ünlü Romalı Avukat Çiçero'ya göre iyi bir savunman 
olabilmek için edebiyat, felsefe, hukuk bilgisi yanı sıra espri yeteneğinin de olması gerekir. Çiçero'a göre avukat rakibini köşeye sıkıştırmayı bilmeli, jüriyi güldürebilmelidir.

Tüm bu açıklamalar adalet dağıtımı ve yargılama faaliyetinin "oyun" kavramıyla yakın ilişki içinde olduğunu kanıtlamaktadır. Şimdi yaratıc1 drama, tiyatro ve hukuk arasındaki akrabalığı irdeleyeceğiz.

Yaratıcı drama, tanımının unsurları arasında yer alan "oyun" kavramı, yukarıdaki açıklamalar çerçevesinde, yaratıcı drama ile hukuk arasındaki ilk güçlü bağı oluşturmaktadır. Ancak bu iki kavram arasındaki bağ bundan ibaret değildir. Tanımdan anlaşılacağı üzere, yaratıcı drama doğaçlama ve rol oynama gibi tiyatro tekniklerinden yoğun olarak yararlanır. Tiyatro ile yargılama faaliyeti arasında da çok yakın "akrabalık" vardır. İlk bakışta tespit edilen çarpıcı benzerlik, mekân açısındandır. Yargılama faaliyetin yürütüldüğü duruşma salonu ile tiyatro etkinliğinin yapıldığı tiyatro salonu karşılaştırıldığında bu benzerlik neredeyse özdeşlik derecesinde ortaya çıkmaktadır. Muhakeme hukukunun en temel ilkelerinden birisi "duruşmaların aleniyeti" ilkesidir. Gerçekten de ilkel dönemlerden bu güne kadar, duruşma bu yönüyle bir gösteridir. Duruşma salonlarının mimarî tasarımında, tiyatroda olduğu gibi seyirci yerleri vardır. Tarih boyunca kamuoyunu ilgilendiren davalarda - özellikle siyasi davalardayargılamanın gösteri boyutu, hukuksal boyutunu geride bırakmıştır. Yargılamanın tiyatro boyutu öne çıktığında seyirci unsuru, yargılamanın diğer unsurlarına göre daha da önem kazanır. $\mathrm{Bu}$ durumda duruşmaların spor salonlarında veya $\mathrm{o}$ davaya özgü inşa edilen yargısal mekânlarda yapıldığ 1 vakidir. $\mathrm{Bu}$ uç örnekler, yargılama faaliyetindeki teatral öğenin varlığını açığa çıkarması bakımından önemlidir.

Yargilama faaliyetinde, kullanılan alan bir sahne olarak düzenlenir ve bu sahnede oynanacak oyunun gereklerine uygun olarak "yargıç kürsüsü”, "sanık sandalyesi” gibi dekorlar vardır.

Tiyatro ve yargılama etkinliği arasındaki diğer bir koşutluk daha önce de değindiğimiz gibi kostümdür. Yargılama faaliyetinin sujeleri olan yargıç, savcı ve avukatlar cüppe, peruka vs. gibi özel kostümlerle yargılama faaliyetine katılılar.

Yargılama faaliyetine katılanların da oynamak durumunda olduğu yasalar ve geleneklerle belirlenmiş rolleri vardır. Yargılama sujeleri verili rolleri canlandırırlar. Hatta, yargılama sonunda verilen hükmün adaletli olup olmadığı davanın tarafları ve kamuoyu nezdinde hükmün dayandığ1 argümanların sağlamlığından çok, yargılama sujelerinin rollerini iyi oynayıp oynamadığıyla ölçülür. Adalet, gösterilmesi gereken bir şeydir. Adalet duygusu, "duruşma" adı verilen gösteriyle yaratılır. Hukuk dilini bilmeyen yurttaş için yargıcin duruşmadaki jest ve mimikleri, onun 20 sayfalık gerekçeli kararından daha fazla adalet veya adaletsizlik içerir.

Duruşma, herhangi bir oyunun içerdiği çatışmayı en yetkin şekilde içermektedir. Tiyatro ile duruşma arasındaki benzerlik, zengin adlî edebiyat yaratılmasına yol açmıştır. Her hangi bir yaşam olayında olmayan dramatik yoğunluk duruşmanın doğasına içkindir. $\mathrm{Bu}$ nedenle herhangi bir yaşam olayını aynen kaydettiğimizde, bir edebi eserin içerdiği çatışmayı, gerilimi çözümü içermeyebilir. Ama bir duruşma, aynen kaydedildiğinde bir tiyatro eseri olarak izlenme potansiyeli taşır.

Yaratıc1 dramanın bir diğer özelliği grup üyelerinin yaşantılarından yola çıkmasıdır. $\mathrm{Bu}$ özellik de, bir davada fazlasıyla mevcuttur. Bir davada sujeler, bir hukuksal sorunla ilgili olarak kendi yaşantılarından ve birikimlerinden yola çıkarak canlandırma ve doğaçlama yapmaktadırlar. Grup üyelerinin yaşantı birikimleri, çağrışımları, anıları yaratıcı dramada olduğu dibi "kurgusal bir gerçeklik" olan "adli gerçeklik" evrenine aktarılır. 
Sonuç olarak, özel bir zaman, mekân, kostüm ve rol oynamayı kullanan oyuncu-seyirci ilişkisini hatırlatan yargilama teknikleriyle oyun, yaratıcı drama ve tiyatro ile yakın ilişki içindedir. Şu halde, hukuk uygulamasında ve eğitiminde yaratıc1 dramadan yararlanma olanaklarının araştırmaya değer bir konu olduğu kabul edilmelidir.

\section{Hukuk Eğitimi ve Uygulamasında Yaratıcı} Dramadan Yararlanma Olanakları

Yargilama ve savunma etkinliği, sadece bilişsel yönü olan bir etkinlik değil; duyuşsal ve devinişsel boyutu da olan bir etkinliktir. Yargıçların, yasaya uygun davranmak, keyfi davranmamak, önyargılarından kurtulmak, tarafsız olmak, aşırıya kaçmamak, makul olmak, etki altında kalmamak, heyecana kapılmamak, dikkat, sükûnet, nezaket gibi etik yükümlülükleri vardır (Dinçkol, 1995, s.159). Keza avukatlar, yazarken ve konuşurken düşüncelerini olgun ve objektif olarak ifade etmek, uyuşmazlığın doğurduğu düşmanlıkların dışında kalmak, sır saklamak, meslek onuruna uygun davranmak, menfaati zit kimselere hizmet etmemek gibi meslek kurallarıyla bağlıdır.

Kuşkusuz bu mesleki yükümlülükler meslek mensupları tarafindan bilinmektedir. Ancak bu bilginin, davranışa dönüştürülmesi "takrir" sisteminin uygulandığ mümkün değildir. Goethe'nin dediği gibi, "bilmek yetmez, uygulamak da gerekir". Bu nedenle hukukçu eğitiminde, hukukçu adayında istendik davranışları geliştirecek eğitim yöntemlerinin kullanılması gerekmektedir. $\mathrm{Bu}$ eğitimin temel özelliği ise yaşantılar yoluyla eğitimdir. Uygulama içindeki kendiliğinden gelişen denemeyanılma yoluyla edinilen informal eğitim, adalet sistemine çok pahalıya mal olmaktadır.

Yaratıcı drama, yaşantıya dayalı olması nedeniyle, özellikle hukuk eğitimi alanında, en etkili olabilecek araçlardan biri olarak gözükmektedir. Yaratıcı dramada kullanılan süreçsel drama ve forum tiyatro gibi yaklaşım ve teknikler hukukçu eğitiminde kullanılabilecek etkin olabilir.

$\mathrm{Bu}$ nedenle, ilköğretimden mesleki eğitime kadar her derecede yaratıcı drama temelli hukuk programları geliștirilmesi, adalet hizmetine kalite getirecek; Ülkemizde "hukukun üstünlüğü" kavramının yaşam bulmasına katkı sağlayabilecektir

Yaratıc1 drama ile hukuk uygulaması arasındaki akrabalık, yaratıcı dramayı eğitimin yanı sıra hukuk uygulamasında da etkin bir araç mevkiine yükseltmektedir. Hukuk uygulaması içinde olanlar, muhakeme geleneklerinin, yazılı muhakeme kurallarından daha güçlü olduğunu; kanununa aykırı (contra leges) uygulamaları ortadan kaldırmanın zorluğunu bilirler. Kültür inşâ etme gücüne sahip yaratıcı drama teknikleri, özellikle avukatlara, mesleklerini icra ederken hukuksal gerçekliğe etkin olarak müdahale etme şansı verebilir.

\section{Sonuç}

Hukuk uygulaması ve eğitiminde yaratıcı drama zengin olanaklar vaat etmektedir. Hukuk eğitiminde teorik bilginin ezberletilmesinden ibaret "anlatım" tekniği yerine yaşantıya dayalı eğitim zorunludur. Hukuk fakülteleri, barolar ve diğer hukuk kurumlarına hukuksal drama konusunda programlar geliştirme sorumluluğu düşmektedir. Yaratıcı drama, hukuksal gerçekliğin yaratılmasina etkin olarak müdahale etmeyi sağlayacak teknikler içermektedir. Bu nedenle yaratıc1 drama tekniklerinin, hukuk uygulamasında da işe koşulması gerekmektedir. 


\section{Kaynaklar}

Adıgüzel, H.Ö. (2006). Yaratıcı drama kavramı, bileşenleri ve aşamaları. Yaratıcı Drama

Dergisi, 1,1,17.

Bozkurt, A. (2006). Hukukun Öyküsü. Ankara: Ankara Barosu Yayınları.

Çamlıbel, F (2003). Adli yargıda hâkim ve savcı adaylarının ve adalet akademisi eğitimi.

Hukuk Öğretimi ve Hukukçunun Ĕgitimi. Ankara: Türkiye Barolar Birliği.

Demirel, Ö. ve Kaya, Z. (2006). Eğitim İle İlgili Temel Kavramlar. Eğitim Bilimine Giriş. Ankara: Pegem A Yayıncılık.

Dinçkol, A. (1995). Hakimin Karar Verme Sürecinde Temel İlkeler. HFSA Hukuk Felsefesi ve

Sosyolojisi Arkivi. İstanbul: Afa Yayınları.

Güran, S. (2003). Hukuk fakültelerinde öğretim; yönetimin değerlendirilmesi; programın

analizi, kadrolar ve öğrenci profili. Hukuk Öğretimi ve Hukukçunun Eğitimi. Uluslarası Toplant1, Türkiye Barolar Birliği, Ankara, 9-11 Ocak.

Huizinga, J. (2006). Homo Ludens Oyunun Toplumsal İslevi Üzerine Bir Deneme (2. Baskı).

(Çev. Mehmet Ali Kılıçbay). İstanbul: Ayrıntı Yayınları.

Karayalçın, Y.(1994). Hukukta ÖğretimKaynaklar-Metot Problem Çözme (Genişletilmiş 4.
Bask1). Ankara: Banka ve Ticaret Hukuku Araştırma Enstitüsü.

Kayhan, F. (2006a). Yargisal mekân politikalarının yargı işlevine etkileri. Ankara Barosu

Hukuk Kurultayl, Ankara, 3-7 Ocak.

Kayhan, F. (2006b). Oyun, yaratıcı Drama ve hukuk. Bursa Barosu Dergisi, 30, 81, 115.

Okvuran, A (2006). Yaratıc1 Dramanın Kullanılacağ1 Alanlar. Prof. Dr. Inci San'a Armağan: Yaratıcı Drama 1985-1998 Yazılar. Ankara: Naturel Yayıncılık (196-198).

Öntaş, H. (2004). Hukuk fakültelerinde drama eğitimi verilmesi niçin gereklidir? Drama Liderliği. Ankara: Oluşum Yayınları

Pekcanitez, H (2006). Hukukta probleme dayalı öğrenim (Aktif eğitim) Dokuz Eylül Üniversitesi Hukuk Fakültesi örneği. Alındığı yer http://www.barobirlik.org.tr.

Üstündağ, T. (1997). Vatandaşlık ve insan haklarl ĕgitimi dersinin ögretiminde yaratıcı dramanın erişiye ve derse yönelik tutumlarına etkisi. Yayınlanmamış yüksek lisans tezi, Ankara: Hacettepe Üniversitesi.

Yeğin, H (2003). Kutsal mekan ve insan ilişkisi. Yayınlanmamış doktora tezi, Samsun: On Dokuz Mayıs Üniversitesi. 


\title{
Creative Drama in Law Education and Practice
}

\author{
Fahrettin KAYHAN
}

Association of Lawyers

Creative drama is an extensive concept that may be used as a method in education as well as it can be a separate course in formal education or on the job training. In this article the possibility of using the creative drama in law education and practice will be examined.

The special conditions of 1930 s became traditional in bachelors' level law education of which the insufficiency is widely accepted. Law is being lectured in crowded classes with a very limited attendance to tutorials by a very limited number of students. Besides the general situation the active education has come up as a result of an alternative method search. Active education is much like creative drama by its participative nature of groups of 15-20 students leaded by the guidance of the trainer based on realistically prepared scenarios. On the other hand, both the law faculties and the bars organize contests such as "fictional hearing", "virtual case", "hypothetical court" partially based on animations that involve creative drama to a certain aspect. However, these contests differ from the creative drama by the limited participation and playeraudience separation.

The terms of "game" and "animation" may not seem to be relevant with the notion "law" for an average perception. Everything related to law is serious and almost holly while "game" is far from seriousness. The game, in deed, is very close to law as the rules are its most distinctive and important aspect.

There are close relationships between game, creative drama and law. Examining the history of trial jurisprudence one can observe the trial takes place as a "contest" from the very ages up today. The most significant formal characteristic of game is that the activity of game being separated from the usual life geometrically. Accordingly, judging event has also been executed as a ritual in expert places organized passably for this function. Another characteristic of game is that it is not accepted as "daily" or "real life". It has its own peculiar and absolute system within its geometrical limits. This system creates its own rules within each game. The rules of a game are absolutely imperious and unquestionable. During a trial, trial jurisprudence makes the rules of the game action. Jurisprudence rules are more formal, rigid and thus more like a game comparing to other rules of law. Creative drama and the "game" concept among its definition factors, compose the first strong link between creative drama and law within the definitions made previously. The link between these two concepts is not consisting of that. As it is obvious by the definition, the creative drama intensely uses the theatrical techniques such as improvisation and role playing. However, the similarities are not limited to behavioral nature. According to principle of publicity, one of the fundamentals of trial law, during ages especially in political trials that attend public attention, the "show" aspect of the hearings went far beyond the legal aspect of the trials. The "audience" factor sets the similarities between the action of trials and theater performances. A hearing covers a conflict of any game; it takes place in a specially designed "stage", with "actors" in proper "costumes". The subjects, 
relating to a legal problem, stage animation and improvisation based on their personal experiences and backgrounds.

Judging and defending activities shall not be just informative. The expected norms such as being objective, free of prejudice, reasonable, careful, kind, and calm are very well accepted by all judges and lawyers. However this provided information shall also become behavioral which seems impossible by the existing lecture education system. Therefore, as the informal education method of trial and error costs a lot to the system of justice, the educational methods that may enhance the desired behaviors shall be applied in law education.

Creative drama shall be considered to be the most effective tool in education by creating experience, especially in the field of law. It is very well known by everybody within the field of law that the traditional implementations of the trials are much stronger than the written rules and are aware how difficult to remove the contra leges applications. Creative drama techniques (e.g. invisible theatre) can affect especially the attorneys-at-law to intervene the legal reality during the practice.

All these characteristics enforce the use of creative drama as it promises fruitful opportunities in law education and practice. Experience based education in law is a must rather than lecture technique that "transfers" the theoretical information.

It's the responsibility of faculties of law, bar associations and other law institutions to develop creative drama programs. 